\title{
No edge effect on quantity of prey captured in the forest-dwelling tetragnathid orb spider Metellina mengei
}

\author{
Madeline A. Richards and Thomas Hesselberg* \\ Department of Zoology, University of Oxford, Oxford, OX1 2PS, UK
}

Submitted: June 1, 2020. Final revision received: August 19, 2020. Accepted: September 22, 2020

\begin{abstract}
Among the most damaging anthropogenic effects for ecosystems is habitat fragmentation. One of its consequences is the creation of edges, which results in more exposed habitats that have different ecological and behavioural effects on the different species that live there. However, the nature and magnitude of these effects remain unknown for most of the animals and plants inhabiting these edge habitats. This study intends to determine if quantity of prey capture by a woodland population of the orb spider Metellina mengei is subjected to edge effects. By observing the prey capture of this species at edge and interior locations of a woodland, we found no significant effects of edge on the number of prey captured or the average prey length. Instead, we found that inclination of the web, but not web area or other measured web parameters, had a significant effect on prey capture. Therefore, this species of spider may be minimally affected by its location within the woodland and more affected by its surrounding microhabitat, which raises the possibility that non-specialised invertebrate predators could be less impacted by fragmentation than generally recognised.
\end{abstract}

\section{Keywords}

Arachnid; foraging behaviour; inclination; prey size; Tetragnathidae; web characteristics

\section{Introduction}

Anthropogenic habitat fragmentation remains one of the main threats to the biodiversity of specialised woodland species best documented in birds (Gardner et al., 2019) and insects (Tscharntke et al., 2002) (but see Fahrig, 2017 for evidence of a negligent or even positive effect of habitat fragmentation for overall biodiversity). This is partly due to reduced overall habitat size and its consequences for populations sizes and their viability, but also due to the increase in edge habitat. These

*) Corresponding author; e-mail: thomas.hesselberg@ zoo.ox.ac.uk 
edges have different properties than the interior and can result in a further reduction of suitable habitat for some species. In woodland, the typical edge conditions include increased wind speed (Tew \& Hesselberg, 2017) and warmer temperatures where animals get more sun exposure (Jokimäki et al., 1998). In general, woodland edges show more fluctuating environmental and ecological conditions than the woodland interior. Habitat fragmentation and edge effects not only lead to changes in species richness and abundance as outlined above, but, although much less studied, they can also result in changes in species composition and in behaviour of species surviving in the edges. This includes changes in vegetation composition as conditions favour more generalist plants and saplings (Jokimäki et al., 1998), reduced hoarding activity in birds (Brotons et al., 2001), increased numbers of larger insects (Jokimäki et al., 1998) and increased insect herbivory and foraging activity (Urbas et al., 2007; Guimarães et al., 2014).

As environmental factors are known to have significant effects on web-building behaviour in orb spiders (Vollrath et al., 1997; Hesselberg, 2015), the different physical conditions at edges may lead to edge effects in spider behaviour. Wind damage to webs reduces the capture area and results in reduced prey capture ability and increased energy cost from the spider in order to mend or rebuild the web (Tew et al., 2015). To reduce the impact of wind damage to a web, some species of orbweaving spiders reduce the capture area, increase mesh height, and increase the strength of their silk when exposed to stronger winds (Vollrath et al., 1997; Liao et al., 2009). Wind has also been shown to negatively affect prey capture success in orb spiders (Turner et al., 2011). On the other hand, increased temperatures could lead to more efficient prey capture (Hesselberg \& Vollrath, 2006) and the increased number of flying insects may also provide more prey (Jokimäki et al., 1998; Tew \& Hesselberg, 2017).

However, a previous study by Tew and Hesselberg (2017) of the orb spider Metellina mengei (Blackwell, 1869), a habitat generalist in the family Tetragnathidae, found that they do not alter their web design between the edge and interior of a woodland despite an increase in wind speed at the edge habitat. It was suggested in their paper that this was because the spiders were trading off potential web damage against higher prey capture rates. This study examines this suggestion by monitoring prey capture of webs of the same spider at the edge and interior of the same temperate woodland - Wytham Woods in Oxfordshire, UK - in order to further understand the role of edge effects on this orb spider.

The orb web itself evolved in the early Jurassic (Dimitrov et al., 2017) and likely arose from a ground sheet or brushed sheet web in response to the evolution of insect flight (Blackledge et al., 2009). The advantage of orb webs over sheet or tangle webs is that they are very difficult for insects to see head on because of their low thread density compared to sheet or tangle webs. However, this comes at the cost of being easily damaged by wind, rain or insects and needing repair or to be rebuilt regularly (Rypstra, 1982; Tew et al., 2015). Metellina mengei - like most species of orb spiders (Foelix, 2011) - dismantle their webs at the end of the day, 


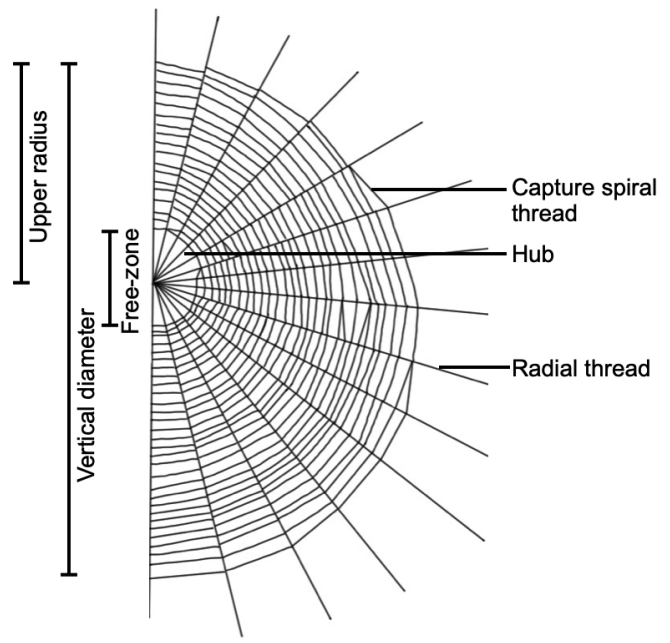

Figure 1. Schematic drawing of half a simplified orb web showing where web measurements were taken. All measurements were taken through the hub in centimetres.

consume the valuable silk, and rebuild them the following day (Peakall, 1971). For this study, this means that prey capture can be monitored on fresh webs every day.

The role of the orb web (see fig. 1) when catching prey is to intercept and stop the insect in flight and hold it long enough for the spider to reach and subdue it. The sticky capture spiral threads are responsible for holding the insect. The high water content of the glue coating them makes these threads stretchier than the frame or radial threads, allowing larger insects to be caught while not being easily broken by struggling prey (Foelix, 2011). The radial threads account for up to $98 \%$ of the web's ability to dissipate flight energy by transferring it to heat as the silk stretches (Sensenig et al., 2012). When a prey item hits the web and is entangled, vibrations are sent through the radii to the hub. Sensors on the legs detect this vibration and the spider orientates itself in the corresponding direction (Klärner \& Barth, 1982; Mortimer et al., 2015). If the prey is then still, the spider can pluck the radial threads and use the echoing vibrations to locate the prey (Klärner \& Barth, 1982; Turner et al., 2011). The spider approaches the prey along the corresponding radii, then bites and wraps the prey to subdue it before carrying it to the hub to eat. If prey items are not quickly reached and immobilised, they are likely to escape (Foelix, 2011).

Certain design aspects of orb webs can increase their likelihood of prey capture, including increased capture area and reduced mesh size (Chacón \& Eberhard, 1980; Liao et al., 2009; Blamires, 2010); closer proximity to flowering plants and increased height of the web in the vegetation (McReynolds, 2000); or decreased height (Chacón \& Eberhard, 1980); a more vertical inclination (Chacón \& Eberhard, 1980; Opell et al., 2006); and asymmetrical webs, which utilise a spider's increased downward speed due to gravity by increasing the area below the hub where the spider is more likely to reach prey before it escapes (Nakata \& Zschokke, 
2010). Orientation of the web has been linked to thermal regulation - with spiders orienting their webs and bodies to either increase or reduce absorption of thermal radiation depending on the circumstances (Biere \& Uetz, 1981; Ramirez et al., 2003). The main aim of this paper is to determine whether proximity to the edge of a woodland habitat will affect the prey capture success of the orb spider $M$. mengei in terms of both the quantity of prey captured and the length of the prey items. However, we will also analyse the effects of web and environmental variables including temperature, height, inclination, orientation, asymmetry and capture area to determine which of these may affect prey capture in $M$. mengei and whether some of these variables differ between webs located at the edge and the interior of the woodland. We hypothesise that web geometry should not differ (Tew \& Hesselberg, 2017), but that webs at the edge of the woodland will capture more and larger prey items given that larger insects are reportedly more numerous and active at the edge (Jokimäki et al., 1998; Urbas et al., 2007).

\section{Materials and methods}

\section{The study organism}

Metellina mengei are common throughout the UK and continental Europe in May and June, where they predominantly inhabit grassland and woodland understory. These spiders are easily identified in the field by their small, inclined orb webs; absence of silk threads in the centre of the hub; and a dark stripe down the ventral side of the abdomen (Bee et al., 2017). Due to the similarity between this species and Metellina segmentata (Bee et al., 2017) - a species that appears in late summer ten specimens of varying-sized female $M$. menge $i$ were collected from the edge and interior of the wood at the start and end of the data collection period. These individuals were stored in ethanol and positively identified as $M$. mengei by examination under a microscope.

\section{Observations}

Wytham Woods, a Site of Special Scientific Interest (SSSI), is owned by Oxford University. Data were collected in the Great Wood using 50-m transects. Edge transects were located on the westernmost path with only one row of trees between the path and open fields. Both the edge and interior were sampled on each day, alternating which was sampled first, beginning with the interior. The transects were labelled on a map to minimise repeated visits, although this became unavoidable near the end of the data-collecting period. Fifteen unique transects were used in total. The vegetation was carefully inspected to identify all possible eligible webs present.

Data were collected on ten days: the 21st, 22nd, 23rd and 29th of May and the 5th, 8th, 11th, 12th, 13th and 18th of June in 2018. Webs were only included in this study if there was an adult female $M$. mengei spider in the hub. Only webs within $3 \mathrm{~m}$ of the path and less than approximately $40 \%$ damaged at the start of the day 
were included. Prey capture was monitored three times a day at 2-h intervals, with any new prey items recorded and their length measured. Length of prey was used as an easily measurable proxy for biomass. Monitoring occurred within the hours that webs were available. The times of the first prey capture data collection were between 10:00 and 13:00 and then in 2-h intervals, meaning the final monitoring took place between 14:00 and 17:00.

When monitoring prey capture the following variables were noted: Time of measurement; location of the transect; web ID number; prey length $(\mathrm{mm})$; location of the prey remains on the web so that they could be distinguished from new prey items later. Temperature and humidity were also measured for the transect and averaged over the day.

Measurements of web variables were made once per day for each web. Several blind repeat measurements were made to confirm consistency. The following web variables were measured (see fig. 1; length measurements are in $\mathrm{cm}$ ): Horizontal diameter, vertical diameter, upper radius, length of vertical free-zone, inclination from the horizontal (to the nearest five degrees), orientation of the upwardly inclined face of the web (using a compass, the bearing the web was facing was taken in degrees from north), direction of the path from the hub (using a compass, the bearing - taken in degrees from north - from the hub of the web towards the closest part of the path was taken) and the height of the web measured from the ground to the hub.

The following web variables were calculated using the measurements above.

Web area (the area of the capture spiral) was calculated using the Ellipse-hub formula described in Herberstein \& Tso (2000), where $D_{\mathrm{v}}$ is the vertical diameter, $D_{\mathrm{h}}$ is the horizontal diameter and $\mathrm{i}$ is the height of the freezone: Area $=\left(D_{\mathrm{v}} \div\right.$ $2)\left(D_{\mathrm{h}} \div 2\right) \pi-(H \div 2)^{2} \pi$.

Web asymmetry was calculated using the following formula, where UR is upper radius and LR is lower radius: (UR - LR) / (UR + LR) from Zschokke (1993). Using this formula, zero indicates the hub is in the centre of the web, $>0$ indicates the hub is lower than the centre and $<0$ indicates the hub is higher than the centre.

Orientation of the web with respect to the path was measured by calculating the smallest angle between a line perpendicular to the plane of the web and the line pointing in the direction of the path. This was calculated from measurements mentioned above: the orientation of the web from north, and the direction of the path from the web. For example, a web parallel to the path would have an angle of zero and a web perpendicular to the path would be at $90^{\circ}$.

\section{Analysis}

$\mathrm{R}$ (R Core Team, 2019) was used to analyse the data. The package ggplot2 (Wickham, 2016) was used to produce the graphs.

A Pearson's $\chi^{2}$ contingency test was conducted to test for any association between the location (edge or interior of the woodland) of webs and prey capture success. The data used for this test were the number of webs that caught one or 
more prey items during the day and the number of webs that caught no prey items in the day.

For the linear models, collinearity between all continuous predictor variables was tested by assessing the correlation coefficient of pairwise variables. Temperature and humidity were found to have a high correlation coefficient (above 0.7) so humidity was removed as a variable. All other variables were able to remain in the model. Due to the high numbers of zeros in the prey capture data, zero-inflated generalised linear mixed models with a Poisson distribution were used in the analysis using the package glmmADMB (Fournier et al., 2012). The total number of prey counted in the web throughout the day acted as the response variable with the following as explanatory variables: web area, edge or interior location, orientation, orientation to the path, web height, inclination, asymmetry and temperature. The date of data collection and the transect were given as random variables. The model was tested for overdispersion by calculating the ratio of $\chi^{2}$ to residual degrees of freedom using the PsychHelperFunctions package (Huff \& Papenmeier, 2017). This ratio was 1.33, suggesting no overdispersion. An Analysis of Deviance table (Type II Wald $\chi^{2}$ tests) using the car package (Fox \& Weisberg, 2019) was used to test the effects of the variables on prey capture. Variables were removed by backward selection until a model was produced containing only significant $P$ values $(<0.05)$.

As well as the total number of prey captured, the potential effect on average size of prey was also tested. A linear mixed model, using the lmer() command from the lme4 package (Bates et al., 2015), used the average length of prey a web captured as the response variable while web area, edge or interior, orientation, orientation to the path, web height, inclination, asymmetry and temperature were explanatory variables and date and transect were again random variables. Only webs that had caught at least one prey item were included. A graph of Pearson's residuals was examined to determine the appropriateness of this model. Variables were removed by backwards selection as above.

To determine whether web variables were affected by edge effects, linear mixed models were run using the lmer() command from the lme4 package (Bates et al. 2015). Inclination, orientation to the path and web area were tested in separate models all against edge or interior location as the predictor variable with date and transect as random variables.

\section{Results}

While prey type was not quantified, the majority appeared to be aphids. The models testing the number of prey in the web used data from 84 webs which caught a total of 122 prey.

Temperatures ranged between $15.1^{\circ} \mathrm{C}$ and $20.3^{\circ} \mathrm{C}$ at edge transects with a mean of $17.0^{\circ} \mathrm{C}$ and between $15.1^{\circ} \mathrm{C}$ and $22.3^{\circ} \mathrm{C}$ at interior transects with a mean of $18.3^{\circ} \mathrm{C}$. 
A.

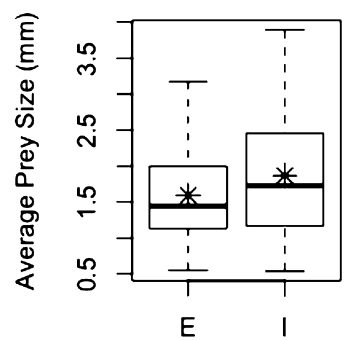

Edge or Interior Location

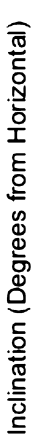

B.

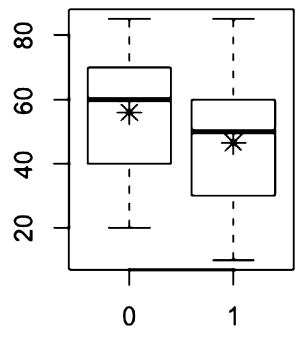

Success

Figure 2. Prey capture in Metellina mengei webs. (A) The average prey length (in $\mathrm{mm}$ ) found in webs at the edge (E) or interior (I) of the woodland. (B) The inclination of webs (in degrees) that caught no prey $(0)$ versus at least one prey item (1). Box plots show medians and interquartile ranges. Stars indicate mean values.

\section{Edge effects}

The percentage of edge webs that caught at least one prey item was $72 \%$, while for interior webs the percentage was $56 \%$. This indicates a difference between success rates in edge and interior webs although a $\chi^{2}$ test showed no significant difference (Df $=1, \chi^{2}=2.3389, P=0.1262$ ). Similarly, our linear model found no significant effects of edge effects on the number of prey (zero-inflated LMM: Df $=1$, $\left.\chi^{2}=0.93, P=0.34\right)$.

Because the energy provided by the prey caught directly relates to the fitness of the spider, the effect on average prey length as a proxy for biomass was also analysed. This model used the 54 webs which had caught at least one prey item during the observation period. Figure $2 \mathrm{~A}$ shows that $M$. mengei webs in the interior of the wood appeared to catch slightly larger prey with a greater variation in length, although the means were very similar (mean length of prey in edge webs: $1.6 \mathrm{~mm}$; mean length in interior webs: $1.9 \mathrm{~mm}$ ). Edge or interior location was not a significant variable in predicting average prey length (LMM: $\mathrm{Df}=1, \chi^{2}=1.45$, $P=0.23)$.

\section{Web characteristics}

Of the variables tested, only inclination was statistically significant in affecting the total number of prey caught (zero-inflated LMM: Df $=1, \chi^{2}=7.48, P=0.006$ ). Figure $3 \mathrm{~A}$ shows that the inclination of the web with the highest prey capture recorded was around $40^{\circ}$ from the horizontal. Less successful webs were more vertical. Webs that caught any prey during the day had an average inclination of $47^{\circ}$ with a standard deviation of 15.6 , while webs that did not catch any prey throughout the day had an average inclination of $56^{\circ}$, with a standard deviation of 17.9 (fig. 2B). Inclination, however, was not a significant factor in predicting prey length (LMM: 

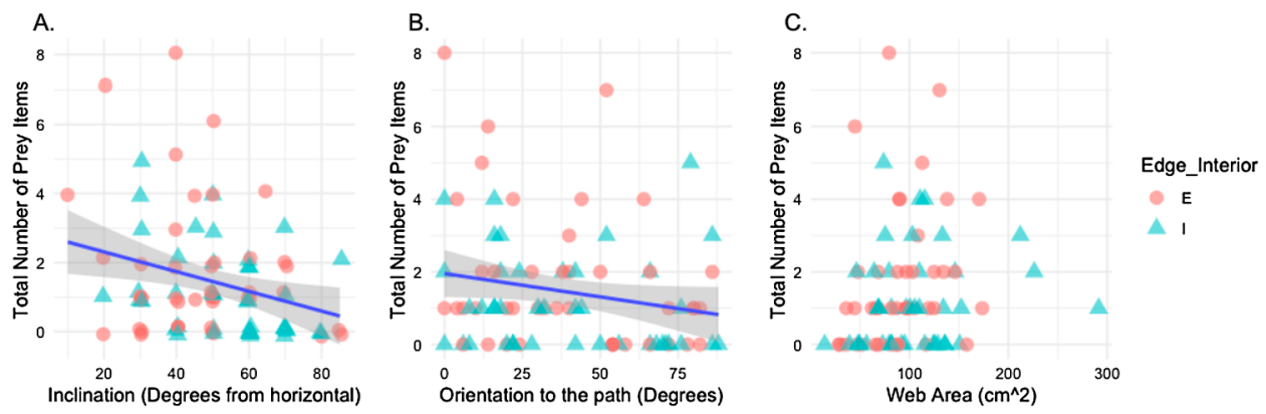

Figure 3. The total number of recorded prey items against: (A) inclination (in degrees; the points in this graph have been jittered); (B) orientation of the web to the path (in degrees); and (C) capture spiral area (in $\mathrm{cm}^{2}$ ). Red circles represent data points from edge locations while blue triangles represent interior locations. Blue lines indicate a linear model best fit for the data.

$\left.\mathrm{Df}=1, \chi^{2}=0.11, P=0.74\right)$. None of the variables tested had a significant effect on prey length.

Inclination was the only variable that appeared to significantly affect prey capture in $M$. mengei orb webs. Therefore, the effect of edge or interior woodland location of the webs on inclination was tested. Figure 4A shows that interior webs were slightly more vertical, although this was not statistically significant (LMM: Df $=1$, $\left.\chi^{2}=3.46, \mathrm{i}=0.063\right)$.

Although no other variables were found to be statistically significant indicators of prey capture, there may be a relationship between orientation of the web with regard to the path and prey capture with prey capture decreasing as the angle between the plane of the web and the path increases (fig. 3B). The mean angle was $39^{\circ}$ with a standard deviation of $27^{\circ}$. Figure $4 \mathrm{~B}$ shows little difference between webs at edge and interior locations of the woodland, supported by a linear mixed model

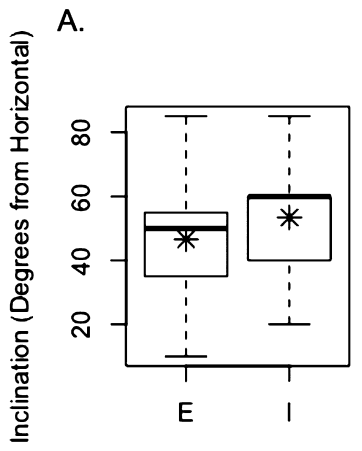

Edge or Interior Location
B.

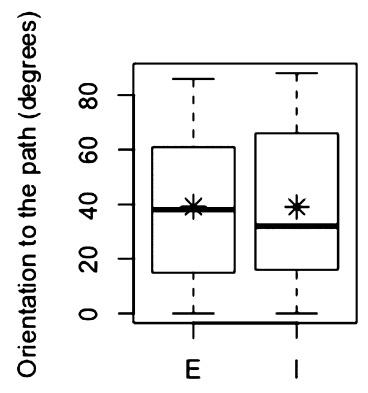

Edge or Interior Location
C.

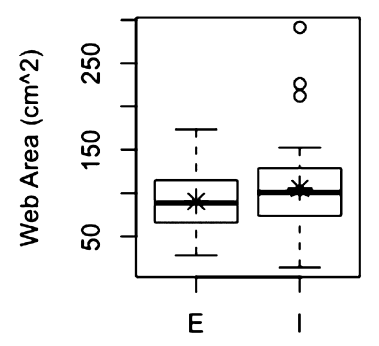

Edge or Interior Location

Figure 4. Web variables in edge or interior locations of the woodland. (A) The inclination of webs (in degrees) found at edge or interior locations. (B) The orientation of webs to the path (in degrees) at edge or interior locations. (C) The area (in centimetres squared) of the capture spiral in webs found at edge or interior locations. Box plots show median and interquartile range. Stars indicate mean values. 
testing whether orientation to the path was affected by location which showed no significant effect (LMM: Df $=1, \chi^{2}=0.09, P=0.981$ ).

The average capture area of webs in this study was $97.9 \mathrm{~cm}^{2}$ with a standard deviation of $45.4 \mathrm{~cm}^{2}$. Somewhat surprisingly, we found no relationship between web area and prey capture (fig. 3C; zero-inflated LMM: Df $=1, \chi^{2}=0.46, P=$ $0.50)$. A linear mixed model to determine whether web area was affected by edge or interior location showed no significant effect (LMM: $\left.\mathrm{Df}=1, \chi^{2}=1.89, P=0.17\right)$. Figure $4 \mathrm{C}$ shows a very similar distribution of web area between edge and interior locations.

\section{Discussion}

\section{Edge effects}

Previous studies have found that flying insects increase in abundance at the edge of woodlands (Jokimäki et al., 1998; Guimarães et al., 2014). However, our study indicates that this does not translate to statistically significant increases in prey capture for $M$. mengei, although a slightly higher percentage of webs at edge locations caught at least one prey item. We also found no significant difference in size of prey between the two sites (fig. 2A), contrary to Jokimäki et al. (1998). This could be due to the similarity between the two habitats, as the interior habitats of the woodland were fairly open because the undergrowth was mowed regularly.

Our findings of no edge effects in web parameters are comparable to those by Tew \& Hesselberg (2017). Their study did find an increase in prey capture for edge webs, although they also found a difference in wind speed between the two sites. The wind speed could not be determined for this study as during the period of data collection the wind was too negligible for the available instruments to measure speed or direction reliably.

\section{Web characteristics}

\section{Inclination}

The variable that was consistently found to be significant in predicting prey capture in this study was inclination. Prey capture was highest for intermediate webs $\left(40^{\circ}\right.$ from horizontal) and decreased as webs became more vertical (fig. 3A). Webs in edge locations appear to be more horizontal than interior webs although this difference is not significant (fig. 4A). Previous studies have found that more vertical webs have higher prey capture rates (Chacón \& Eberhard, 1980; Opell et al., 2006). However, one of these studies only considered completely vertical versus completely horizontal webs (Opell et al., 2006), while the other used web-like traps in an open field rather than in a woodland (Chacón \& Eberhard, 1980). The intermediate inclination of the webs of $M$. mengei could be a compromise between more vertical webs which are more effective at catching larger flying insects in the open and horizontal webs that are more effective for small, light insects alighting 
from the surface of water bodies or vegetation (Foelix, 2011). Small insects, mainly aphids, made up most of $M$. mengei's prey capture in this study.

\section{Orientation to the path}

Although not statistically significant, orientation to the path was shown to be a potential factor affecting prey capture, with webs facing the open space of the path having a higher prey capture on average. Previous studies have linked web orientation to thermal regulation with regard to the position of the sun (Biere \& Uetz, 1981; Ramirez et al., 2003). However, M. mengei make webs within the vegetation so are shaded from the sun. Therefore, it is possible that orientation in this species may be more to do with enhancing the prey capture ability of the web as webs that are aligned to a large open space may take advantage of insects flying in and out of the vegetation.

\section{Web area}

We did not find web area to be a significant factor in predicting prey capture. This is inconsistent with many previous studies which find increasing web area to be an indicator of increased prey capture (Liao et al., 2009). While Tew \& Hesselberg (2017) did not find web area to be significantly different between edge and interior habitats for M. mengei (fig. 4C), Liao et al. (2009) found that Cyclosa webs in windier habitats were built smaller and more densely than those of a species that live in sheltered habitats. Individual spiders of the species Argiope keyserlingi have been shown to adjust their web area in response to frequency of feeding (Blamires, 2010). The lack of a significant influence of web area in this study is surprising, but it could be due to a number of factors, such as a lack of sufficient data to make any trends clearer, or an overriding effect of local habitat on the prey capture abilities of the web.

\section{Prey length}

A potential shortcoming of this study is that, according to Venner \& Casas (2005) and Blackledge (2011), spiders rely on rare encounters with large prey rather than regular capture of small prey items. This could suggest that using numbers of prey captured as a metric of web success is not useful. In this study, almost all prey was of a similar size. The largest prey item found was $12.6 \mathrm{~mm}$ in length. However, the mean length was $1.8 \mathrm{~mm}$ and only 12 of the 122 prey items in this study were larger than $3 \mathrm{~mm}$. This suggests that $M$. mengei rely on frequent small prey rather than very rare large prey and that quantity of prey is likely to be correlated with biomass and therefore useful in assessing web success. Small prey caught in webs were occasionally observed being consumed so must have offered benefit to the spider. Also, if a web is successful at catching prey in general it is likely that some of that prey will be "large". Furthermore, the "rare, large prey" hypothesis is disputed. A paper by Harmer et al. (2015) suggests that large prey make up only a tiny percentage of total biomass in large webs and so it is unlikely these are essential for a spider's growth and reproduction. The calculations made in the Blackledge 
(2011) paper to estimate biomass based on prey length which supported the "rare, large prey" hypothesis have also been critiqued (Eberhard, 2013).

\section{Conclusion}

In this study, we found no statistically significant effect of edge on the quantity or length of prey captured by Metellina mengei, or on web parameters that may affect prey capture. This is consistent with the findings of Tew \& Hesselberg (2017) that edge had no effect on web geometry and indicates that this species is not negatively affected by fragmentation of its habitat when discounting habitat reduction, consistent with the findings of Fahrig (2017). A better understanding of the effects of edges on individual species is important for predicting the effects of fragmentation on overall biodiversity and its consequences for conservation (Harris, 1988). To better understand what influences prey capture in Metellina mengei, and other small species of woodland spiders, more research into the effects of the surrounding microhabitat is needed.

\section{Acknowledgements}

We thank Nigel Fisher for allowing us access to Wytham Woods. This study did not receive external funding, but we would like to thank the Department of Zoology at the University of Oxford for support.

\section{References}

Bates, D., Mächler, M., Bolker, B. \& Walker, S. (2015) Fitting linear mixed-effects models using lme4. J. Stat. Softw., 67, 1-48. DOI:10.18637/jss.v067.i01.

Bee, L., Oxford, G. \& Smith, H. (2017) Britain's Spiders: a Field Guide. WILDGuides/Princeton University Press, Princeton, NJ, USA.

Biere, J.M. \& Uetz, G.W. (1981) Web orientation in the spider Micrathena gracilis (Araneae: Araneidae). Ecology, 62, 336-344. https://doi.org/10.2307/1936708.

Blackledge, T.A. (2011) Prey capture in orb weaving spiders: are we using the best metric? J. Arachnol., 39, 205-210. https://doi.org/10.1636/Chi10-52.1.

Blackledge, T.A., Scharff, N., Coddington, J.A., Szuts, T., Wenzel, J.W., Hayashi, C.Y. \& Agnarsson, I. (2009) Reconstructing web evolution and spider diversification in the molecular era. Proc. Natl Acad. Sci. USA, 106, 5229-5234. https://doi.org/10.1073/pnas.0901377106.

Blamires, S.J. (2010) Plasticity in extended phenotypes: orb web architectural responses to variations in prey parameters. J. Exp. Biol., 213, 3207-3212. DOI:10.1242/jeb.045583.

Brotons, L., Desrochers, A. \& Turcotte, Y. (2001) Food hoarding behaviour of black-capped chickadees (Poecile atricapillus) in relation to forest edges. Oikos, 95, 511-519. https://doi.org/10.1034/ j.1600-0706.2001.950316.x.

Chacón, P. \& Eberhard, W.G. (1980) Factors affecting numbers and kinds of prey caught in artificial spider webs, with consideration of how orb webs trap prey. Bull. Br. Arachnol. Soc., 5, 29-38. 
Dimitrov, D., Benavides, L.R., Arnedo, M.A., Giribet, G., Griswold, C.E., Scharff, N. \& Hormiga, G. (2017) Rounding up the usual suspects: a standard target-gene approach for resolving the interfamilial phylogenetic relationships of ecribellate orb-weaving spiders with a new family-rank classification (Araneae, Araneoidea). Cladistics, 33, 221-250. https://doi.org/10.1111/cla.12165.

Eberhard, W.G. (2013) The rare large prey hypothesis for orb web evolution: a critique. J. Arachnol., 41, 76-80. https://doi.org/10.1636/B12-34.1.

Fahrig, L. (2017) Ecological responses to habitat fragmentation per se. Annu. Rev. Ecol. Evol. Syst., 48, 1-23. https://doi.org/10.1146/annurev-ecolsys-110316-022612.

Foelix, R.F. (2011) Biology of Spiders. 3rd Edition. Oxford University Press, Oxford, UK.

Fournier, D.A., Skaug, H.J., Ancheta, J., Ianelli, J., Magnusson, A., Maunder, M.N., Nielsen, A. \& Sibert, J. (2012) AD model builder: using automatic differentiation for statistical inference of highly parameterized complex nonlinear models. Optim. Methods Softw., 27, 233-249. https://doi.org/10. 1080/10556788.2011.597854.

Fox, J. \& Weisberg, S. (2019) An $\{R\}$ Companion to Applied Regression. 3rd Edition. Sage Publications, Thousand Oaks, CA, USA. https://socialsciences.mcmaster.ca/jfox/Books/Companion/.

Gardner, E., Hesselberg, T., Grabowska-Zhang, A. \& Hughes, J. (2019) The effect of woodland area on avian community composition in a fragmented southern UK landscape and associated management recommendations. Bird Study, 66, 293-305. https://doi.org/10.1080/00063657.2019.1656707.

Guimarães, C.D.D.C., Viana, J.P.R. \& Cornelissen, T. (2014) A meta-analysis of the effects of fragmentation on herbivorous insects. Environ. Entomol., 43, 537-545. https://doi.org/10.1603/ EN13190.

Harmer, A.M.T., Clausen, P.D., Wroe, S. \& Madin, J.S. (2015) Large orb-webs adapted to maximise total biomass not rare, large prey. Sci. Rep., 5, 14121. https://doi.org/10.1038/srep14121.

Harris, L.D. (1988) Edge effects and conservation of biotic diversity. Conserv. Biol., 2, 330-332.

Herberstein, M.E. \& Tso, I.-M. (2000) Evaluation of formulae to estimate the capture area and mesh height of orb webs (Araneoidea, Araneae). J. Arachnol., 28, 180-184. https://doi.org/10.1636/ 0161-8202(2000)028[0180:EOFTET]2.0.CO;2.

Hesselberg, T. (2015) Exploration behaviour and behavioural flexibility in orb-web spiders: a review. Curr. Zool., 61, 313-327. https://doi.org/10.1093/czoolo/61.2.313.

Hesselberg, T. \& Vollrath, F. (2006) Temperature affects both web spider response time and prey escape speed. Bull. Br. Arachnol. Soc., 13, 275-280.

Huff, M. \& Papenmeier, F. (2017) PsychHelperFunctions: common helper functions for psychological data analysis. R package version 0.3.6.

Jokimäki, J., Huhta, E., Itämies, J. \& Rahko, P. (1998) Distribution of arthropods in relation to forest patch size, edge, and stand characteristics. Can. J. For. Res., 28, 1068-1072. https://doi.org/10. 1139/X10-126.

Klärner, D. \& Barth, F.G. (1982) Vibratory signals and prey capture in orb-weaving spiders (Zygiella x-notata, Nephila clavipes; Araneidae). J. Comp. Physiol., 148, 445-455. https://doi.org/10.1007/ BF00619783.

Liao, C.-P., Chi, K.-J. \& Tso, I.-M. (2009) The effects of wind on trap structural and material properties of a sit-and-wait predator. Behav. Ecol., 20, 1194-1203. https://doi.org/10.1093/beheco/arp119.

McReynolds, C.N. (2000) The impact of habitat features on web features and prey capture of $A r$ giope aurantia (Araneae, Araneidae). J. Arachnol., 28, 169-179. https://doi.org/10.1636/01618202(2000)028[0169:TIOHFO]2.0.CO;2.

Mortimer, B., Holland, C., Windmill, J.F.C. \& Vollrath, F. (2015) Unpicking the signal thread of the sector web spider Zygiella x-notata. J. R. Soc. Interface., 12, 20150633. https://doi.org/10.1098/ rsif.2015.0633. 
Nakata, K. \& Zschokke, S. (2010) Upside-down spiders build upside-down orb webs: web asymmetry, spider orientation and running speed in Cyclosa. Proc. R. Soc. B Biol. Sci., 277, 3019-3025. https:// doi.org/10.1098/rspb.2010.0729.

Opell, B.D., Bond, J.E. \& Warner, D.A. (2006) The effects of capture spiral composition and orbweb orientation on prey interception. Zoology, 109, 339-345. https://doi.org/10.1016/j.zool.2006. 04.002.

Peakall, D.B. (1971) Conservation of web-proteins in the spider, Araneus diadematus. J. Exp. Zool., 176, 257-264. https://doi.org/10.1002/jez.1401760302.

R Core Team (2019) R: a Language and Environment for Statistical Computing. R Foundation for Statistical Computing, Vienna, Austria. https://www.R-project.org/.

Ramirez, M.G., Wall, E.A. \& Medina, M. (2003) Web orientation of the banded garden spider Argiope trifasciata (Araneae, Araneidae) in a California coastal population. J. Arachnol., 31, 405-411. https://doi.org/10.1636/S01-40.

Rypstra, A.L. (1982) Building a better insect trap; an experimental investigation of prey capture in a variety of spider webs. Oecologia, 52, 31-36. https://doi.org/10.1007/BF00349008.

Sensenig, A.T., Lorentz, K.A., Kelly, S.P. \& Blackledge, T.A. (2012) Spider orb webs rely on radial threads to absorb prey kinetic energy. J. R. Soc. Interface., 9, 1880-1891. https://doi.org/10.1098/ rsif.2011.0851.

Tew, E.R., Adamson, A. \& Hesselberg, T. (2015) The web repair behaviour of an orb spider. Anim. Behav., 103, 137-146. https://doi.org/10.1016/j.anbehav.2015.02.016.

Tew, N. \& Hesselberg, T. (2017) The effect of wind exposure on the web characteristics of a tetragnathid orb spider. J. Insect Behav., 30, 273-286. https://doi.org/10.1007/s10905-017-9618-0.

Tscharntke, T., Steffan-Dewenter, I., Kruess, A. \& Thies, C. (2002) Characteristics of insect populations on habitat fragments: a mini review. Ecol. Res., 17, 229-239. https://doi.org/10.1046/j.14401703.2002.00482.x.

Turner, J., Vollrath, F. \& Hesselberg, T. (2011) Wind speed affects prey-catching behaviour in an orb web spider. Naturwissenschaften, 98, 1063-1067. https://doi.org/10.1007/s00114-011-0854-4.

Urbas, P., Araújo Jr, M.V., Leal, I.R. \& Wirth, R. (2007) Cutting more from cut forests: edge effects on foraging and herbivory of leaf-cutting ants in Brazil. Biotropica, 39, 489-495. https://doi.org/ 10.1111/j.1744-7429.2007.00285.x.

Venner, S. \& Casas, J. (2005) Spider webs designed for rare but life-saving catches. Proc. R. Soc. B Biol. Sci., 272, 1587-1592. https://doi.org/10.1098/rspb.2005.3114.

Vollrath, F., Downes, M. \& Krackow, S. (1997) Design variability in web geometry of an orb-weaving spider. Physiol. Behav., 62, 735-743. https://doi.org/10.1016/S0031-9384(97)00186-8.

Wickham, H. (2016) ggplot2: Elegant Graphics for Data Analysis. Springer-Verlag, New York, NY, USA.

Zschokke, S. (1993) The influence of the auxiliary spiral on the capture spiral in Araneus diadematus Clerk (Araneidae). Bull. Br. Arachnol. Soc., 9, 169-173. 